\title{
Role of Demographic Factors on National Health Insurance Uptake among Informal Sector Workers in Vihiga Sub County, Vihiga County, Kenya: A Cross-Sectional Study
}

\begin{abstract}
Muranda MA ${ }^{1 *}$, Owenga JA' ${ }^{2}$, Otieno $\mathrm{DO}^{1}$, Onguru $\mathrm{DO}^{1}$ and Orende $\mathrm{MA}^{1}$
${ }^{1}$ School of Health Sciences, Jaramogi Oginga Odinga University of Science and Technology, Kenya

${ }^{2}$ In-depth Research Services Institute of Health and Social Work Nairobi, Kenya
\end{abstract}

* Corresponding author: Marion Agiza Muranda, School of Health Sciences, Jaramogi Oginga Odinga University of Science and Technology, Bondo, Kenya, Tel: +254 719657831; Email: mayaagiza@live.com

\section{Research Article \\ Volume 5 Issue 1}

Received Date: December 03, 2020

Published Date: January 04, 2021

DOI: $10.23880 /$ phoa-16000169

\section{Abstract}

Aim: The aim of the study was to determine the role of demographic factors on uptake of National Health Insurance among the informal sector workers in Vihiga Sub-County.

Subject and Methods: The target population for the purpose of this study was the informal sector workers from Vihiga Sub County drawn from the four wards in the Sub County. Sampling was done using cluster sampling and simple random sampling techniques, to obtain a representative sample of 384. Data was collected using semi-structured questionnaires and analyzed using descriptive statistics. Bivariate and multivariate logistic regression were used to test for associations $(\mathrm{p}<0.05)$.

Results: The mean age of respondents who participated in the study was 42.42 . The results showed that older persons above 50 years, women, high level of education, high income, female headed households and formal employment were significantly associated with uptake of national health insurance.

Conclusion: age, gender, gender of the household head, level of education, employment status and household monthly income had significant influence on uptake of national health insurance. Enrollment should be encouraged among the youth and the male category, this will ensure that they have access to recommended care, receive quality care, and experience better health outcomes.

Keywords: Demographic Factors; National Health Insurance; Health Insurance; Informal Sector Workers

Abbreviations: KNBS: Kenya National Bureau of Statistics; SID: Society for International Development; NHIS: National Health Insurance Scheme; KSh: Kenya Shillings.

\section{Introduction}

The major aim of all health care systems is provision of equal access to health care for everyone. However, social inequalities in health and health care utilization can be found in nearly all European welfare states, health insurance also brings about these inequalities [1]. Given the high demand for healthcare services and extreme under-utilization of health services brought about by financial barriers, health insurance is recommended as one of the major ways of financing healthcare and a promising alternative to other financing methods like cost-recovery and user fees. It's 
further expected that health insurance will improve access to quality healthcare [2]. Several models confirm that demand for health care services is determined by demographic factors. The demand for health care is attributed to education, income, age, insurance, involuntary unemployment. An individual inherits an initial health stock that depreciates with age and can be increased by investment [3]. The likelihood of insurance enrolment has overtime proved to increase with age $[2,4,5]$. Women are more likely to seek care for a health problem, have compulsory insurance and use private health care [6]. They are more likely to renew their health insurance as compared to male respondents [7]. However Wielen VDN, et al. [8] noted a higher coverage amongst men compared to women. In the studies by Cantiello J, et al. [9], Oraro T, et al. [10] no specific gender was pointed out.

Increase in education significantly increases insurance affiliation Duku S, [2], Kimani JK, et al. [5], Wielen VDN, et al. [8], Maina JM, et al. [11], Mukhwana E, et al. [12]. Lack of access to quality medical care was responsible for widening the mortality gap between groups of higher education and lower education [13]. Community Based Health Insurance Uptake was determined by the level of education of an individual [14]. Previous studies by Boateng D, et al. [7], Perlman F, et al. [6] however concluded there's no significant association between the education level and enrollment into health insurance scheme. Several studies have reported a positive correlation between being married and enrollment in an insurance scheme $[2,5,11,15]$. The impact of marital status varies by gender, with single women significantly less likely, and cohabiting men significantly more likely, to lack cover thus seeking professional help than their married counterparts [6]. However Manortey S, et al. [16] reported on marital status as having no significant statistical effect in determining the enrollment into the program. Religion has not been discussed in detail in some of the reviewed articles but has been stated. The results for religious affiliation had different outcomes [4]. However there was significant association between religion and enrollment [7].

The characteristics of a household head influences enrolment into a health insurance scheme. There was likelihood for an entire household to enroll in the program given the level of formal education attained by the family head as compared to those with no formal education [16]. Femaleheaded households were more likely to be insured compared to their counterparts in male-headed households [5] this was contrary to Fadlallah R, Oraro $\mathrm{T}[4,10]$ who reported that male-headed households were more likely to enroll. Household size and household income have no significant influence on uptake of health insurance [10,11]. Household heads that were self-employed or had no fixed employment were significantly less likely to enroll in the scheme. Larger households were willing to pay higher amounts than relatively smaller households and in case they dropped out of the scheme it was as a result of the huge financial burden they face when they seek health care [14]. The present study determines the role of demographic factors on uptake of national health insurance among informal sector workers in Vihiga Sub County. The results could be useful in contributing to understand the influence of demographic factors on health insurance enrolment and to inform relevant policies that encourage uptake of health insurance.

\section{Methods}

This study was conducted in Western region in Kenya in Vihiga County, Vihiga Sub-County. A cross sectional study design was used to collect data on the role of demographic factors on National Health Insurance Uptake. The target population for the purpose of this study was the informal sector workers from Vihiga Sub County. However data on informal sector workers in Vihiga Sub County is not known, given the fact that the sub-county is majorly rural the researcher therefore used data of the employment population in Vihiga Sub-County. Sampling was done using cluster sampling and simple random sampling techniques. To obtain a representative sample of informal sector workers, cluster sampling was done by ward that is Lugaga/ Wamuluma, South Maragoli, Central Maragoli and Mungoma. Having data on the target population the researcher then used co-efficient of variation to calculate the sample that was used from each ward. The calculated sample size of each ward was then be multiplied by a co-efficient of variation (0.4754) of the population by gender in order to obtain the number of males that was sampled from each of the four wards and the remaining ones after subtraction was considered as female as in Table 1 below. In this case the co-efficient of variation ( $r$ ) of the entire population was used because even with the calculation by wards the variation was the same. Simple random sampling technique was then used to select participants from both the male and female categories. According to KNBS and SID [17] the total population of Vihiga Sub-County is 90602 with 43708 males and 47524 females. Hence the Co-efficient of variation ( $r$ ) was calculated as shown below.

$$
\begin{gathered}
r=43078 / 90602 \\
r=0.4754
\end{gathered}
$$




\begin{tabular}{|c|c|c|c|c|c|}
\hline \multirow{2}{*}{ Ward } & Population By & Co-Efficient of Variation & Sample Size By & \multicolumn{2}{|c|}{$\begin{array}{c}\text { Sample Size Distribution By } \\
\text { Gender }\end{array}$} \\
\cline { 4 - 6 } & Employment & & Male & Female \\
\hline $\begin{array}{c}\text { Lugaga/ } \\
\text { Wamuluma }\end{array}$ & 14,438 & $14438 / 45141 \times 384$ & 123 & 59 & 64 \\
\hline South Maragoli & 9,248 & $9248 / 45141 \times 384$ & 79 & 38 & 41 \\
\hline Central Maragoli & 11,998 & $11998 / 45141 \times 384$ & 102 & 49 & 53 \\
\hline Mungoma & 9,457 & $9457 / 45141 \times 384$ & 80 & 38 & 42 \\
\hline TOTAL & 45,141 & & 384 & 184 & 200 \\
\hline
\end{tabular}

Table 1: Distribution of Target Population by Employment and Sample Size Distribution. Source: [17]

A semi-structured questionnaire was used to collect the required information from the respondents. The study used trained and qualified research assistants to assist with the questionnaire distribution. The researcher and the assistants collected data from respondents by asking them questions and recording the responses. Descriptive statistics and logistic regression were used to analyze the data. The analyzed data were organized and summarized using tables. The logistic regression was used to detect for association among study variables. Ethical approval to conduct the study was obtained from the Ethical Review Committee at Jaramogi Oginga Odinga Teaching and Referral Hospital after which the license to conduct the study was Obtained from national commission for Science, technology \& innovation (License No: NACOSTI/P/20/4927). Permission to conduct the study was sought from the relevant county, sub county and local authorities. The researcher explained to the respondents that the study was for academic purposes only. It was made clear that the participation was voluntary. The participants were given informed consent to make the choice to participate or not. They were guaranteed that their privacy was protected by strict standard of anonymity.

\section{Results}

Table 2 below shows socio-demographic characteristics of the respondents by health insurance enrolment. The mean age of respondents who participated in the study was 42.42 . The distribution by age shows that $184(47.92 \%)$ respondents of age between 30 and 49 years old, 58(31.52\%) enrolled for national health insurance. The distribution in terms of gender reveals that majority of the respondents were female $200(52.08 \%)$ of which $81(40.50 \%)$ enrolled in national health insurance. Respondents were asked to state their marital status, there were $247(64.32 \%)$ married respondents and majority $160(64.78 \%)$ did not enroll for national health insurance. The distribution of the respondents by religion shows that majority of the respondents $332(86.46 \%)$ were Christians and majority 218(65.66\%) of the Christians did not enroll for national health insurance. Respondents that never had religion were $8(2.08 \%)$. The respondents were asked to state the gender of household head, majority 292(76.04\%) were male while 92(23.96\%) were female. Out of 292 respondents who stated that household head was male, majority $192(65.75 \%)$ did not enroll for national health insurance. The distribution of respondents in terms of level of education shows that majority of the respondents $86(22.40 \%)$ completed tertiary level of education and $48(55.81 \%)$ of them enrolled for national health insurance. The results further reveal that majority $20(90.91 \%)$ of the respondents who did not have any level of education never enrolled for national health insurance.

In terms of employment, majority $153(39.84 \%)$ were self-employed and in this category $103(67.32 \%)$ did not enroll for national health insurance. Distribution of health insurance uptake with formal employment reveals that majority $34(87.18 \%)$ of the 39 respondents who were doing formal jobs enrolled for national health insurance. The results further reveal that $93(83.78 \%)$ of the unemployed respondents did not enroll for national health insurance. With respect to monthly income, majority of the respondents $169(44.01 \%)$ were earning a monthly of less than Ksh 5000 and $138(81.66 \%)$ of them did not enroll for health insurance. Those earning Ksh 15000 and above per month were $43(11.20 \%)$ and $32(74.42 \%)$ of them enrolled for national health insurance. It is revealed in Table 2 that of the 123 respondents in Lugaga, 84(68.29\%) did not register for national health insurance. The respondents sampled in Central Maragoli was 102 and 62(60.78\%) did not register for national health insurance. It is also clear that 27(33.75\%) out of 80 respondents in Mungoma and 26(32.91\%) out of 79 in South Maragoli registered for national health insurance. 


\begin{tabular}{|c|c|c|c|}
\hline \multicolumn{4}{|c|}{ Health Insurance Enrolment } \\
\hline Factors & $\mathrm{N}(\%)$ & Yes n (\%) & No $n(\%)$ \\
\hline \multicolumn{4}{|c|}{ Age group, mean(SD)=42.42(15.08) } \\
\hline$<30$ & $81(21.09)$ & $18(22.22)$ & $63(77.78)$ \\
\hline $30-49$ & $184(47.92)$ & $58(31.52)$ & $126(68.48)$ \\
\hline $50+$ & $119(30.99)$ & $56(47.06)$ & $63(52.94)$ \\
\hline \multicolumn{4}{|c|}{ Gender } \\
\hline Male & $184(47.92)$ & $51(27.72)$ & $133(72.28)$ \\
\hline Female & $200(52.08)$ & $81(40.5)$ & $119(59.5)$ \\
\hline \multicolumn{4}{|c|}{ Marital Status } \\
\hline Married & $247(64.32)$ & $87(35.22)$ & $160(64.78)$ \\
\hline Single & $76(19.79)$ & $25(32.89)$ & $51(67.11)$ \\
\hline Widowed & $43(11.20)$ & $14(32.56)$ & $29(67.44)$ \\
\hline Divorced & $18(4.69)$ & $6(33.33)$ & $12(66.67)$ \\
\hline \multicolumn{4}{|c|}{ Religion } \\
\hline Christian & $332(86.46)$ & $114(34.34)$ & $218(65.66)$ \\
\hline Muslim & $43(11.20)$ & $16(37.21)$ & $27(62.79)$ \\
\hline Hindu & $1(0.26)$ & $1(100.00)$ & $0(0.00)$ \\
\hline None & $8(2.08)$ & $1(12.5)$ & $7(87.5)$ \\
\hline \multicolumn{4}{|c|}{ House Hold Head Gender } \\
\hline Female & $92(23.96)$ & $32(34.78)$ & $60(65.22)$ \\
\hline Male & $292(76.04)$ & $100(34.25)$ & $192(65.75)$ \\
\hline \multicolumn{4}{|c|}{ Level of Education } \\
\hline None & $22(5.73)$ & $2(9.09)$ & $20(90.91)$ \\
\hline Primary incomplete & $32(8.33)$ & $0(0.00)$ & $32(100)$ \\
\hline Primary complete & $45(11.72)$ & $10(22.22)$ & $35(77.78)$ \\
\hline Secondary incomplete & $36(9.38)$ & $6(16.67)$ & $30(83.33)$ \\
\hline Secondary complete & $143(37.24)$ & $60(41.96)$ & $83(58.04)$ \\
\hline Tertiary incomplete & $20(5.21)$ & $6(30.00)$ & $14(70.00)$ \\
\hline Tertiary complete & $86(22.40)$ & $48(55.81)$ & $38(44.19)$ \\
\hline \multicolumn{4}{|c|}{ Employment Status } \\
\hline Unemployed & $111(28.91)$ & $18(16.22)$ & $93(83.78)$ \\
\hline Casual worker & $81(21.09)$ & $30(37.04)$ & $51(62.96)$ \\
\hline Formal employed & $39(10.16)$ & $34(87.18)$ & $5(12.82)$ \\
\hline Self employed & $153(39.84)$ & $50(32.68)$ & $103(67.32)$ \\
\hline \multicolumn{4}{|c|}{ Monthly Income } \\
\hline$<$ Ksh 5000 & $169(44.01)$ & $31(18.34)$ & 138(81.66) \\
\hline Ksh $5000-10000$ & $110(28.65)$ & $39(35.45)$ & $71(64.55)$ \\
\hline Ksh $10001-15000$ & $62(16.15)$ & $30(48.39)$ & $32(51.61)$ \\
\hline >Ksh 15000 & $43(11.20)$ & $32(74.42)$ & $11(25.58)$ \\
\hline
\end{tabular}




\begin{tabular}{|c|c|c|c|}
\hline \multicolumn{3}{|c|}{ Ward } & $84(68.29)$ \\
\hline Lugaga & $123(32.03)$ & $39(31.71)$ & $62(60.78)$ \\
\hline Central Maragoli & $102(26.56)$ & $40(39.22)$ & $53(66.25)$ \\
\hline Mungoma & $80(20.83)$ & $27(33.75)$ & $53(67.09)$ \\
\hline
\end{tabular}

Table 2: Socio-Demographic Characteristics by Health Insurance Enrolment.

\section{Bivariate Analysis}

Table 3 represents the results of logistic regression. Bivariate analysis involved the use binary logistic regression to determine socio-demographic factors influencing uptake of national health insurance at a confidence level of $95 \%$. The results clearly show that age, gender, gender of the household head, level of education, employment status and household monthly income were statistically significant. With respect to age, it was found that older people (50+ years) were 3.11 times more likely to enroll for national health insurance as compare to people of less than 30 years old. The results show that female category were 1.78 times more likely to enroll for national health insurance in comparison to the male category. It is further revealed that if the household head is male, the respondent was 0.62 times less likely to enroll for national health insurance as compared to if the household head is female. A respondent with secondary education is 7.23 times more likely to enroll for national health insurance as compared to those with no education. The results further reveal that respondents who complete tertiary level of education were 12.63 time more likely to enroll for national health insurance in comparison to those who had no formal education.

Employment status was found to be a significant factor on the uptake of national health insurance. Casual workers were 3.04 times more likely to enroll for national health insurance as compared to unemployed category. In addition, formal employed people were 35.13 times more likely to enroll for national health insurance as compared to those who did not have jobs. The result further confirms that household monthly income influence the uptake of national health insurance. Considering those who were earning less than Ksh 5000 per month as the reference category, those earning KSh 5000 to KSh 10000 were 2.45 times more likely to enroll for national health insurance. Those who were earning ksh.10001 to KSh. 15000 were 4.17 times more likely to enroll for national health insurance and those who were earning over KSh 15000 were 12.95 times more likely to enroll for national health insurance.

\begin{tabular}{|c|c|c|c|c|c|}
\hline \multirow{2}{*}{$\begin{array}{l}\mathrm{N}=\mathbf{3 8 4} \\
\text { Factors }\end{array}$} & \multicolumn{5}{|c|}{ Uptake of National Health Insurance } \\
\hline & Yes n (\%) & No n (\%) & OR & 95\%CI & p-value \\
\hline \multicolumn{6}{|c|}{ Age Group } \\
\hline$<30$ & $18(22.22)$ & $63(77.78)$ & & - & - \\
\hline $30-49$ & $58(31.52)$ & $126(68.48)$ & 1.61 & $0.88-2.96$ & 0.125 \\
\hline 50 and above & $56(47.06)$ & $63(52.94)$ & 3.11 & $1.65-5.87$ & $<0.001$ \\
\hline \multicolumn{6}{|c|}{ Gender } \\
\hline Male & $51(27.72)$ & $133(72.28)$ & & - & - \\
\hline Female & $81(40.5)$ & $119(59.5)$ & 1.78 & $1.16-2.73$ & 0.009 \\
\hline \multicolumn{6}{|c|}{ Marital Status } \\
\hline Married & $87(35.22)$ & $160(64.78)$ & & - & - \\
\hline Single & $25(32.89)$ & $51(67.11)$ & 0.9 & $0.52-1.55$ & 0.709 \\
\hline Widowed & $14(32.56)$ & $29(67.44)$ & 0.89 & $0.45-1.77$ & 0.735 \\
\hline Divorced & $6(33.33)$ & $12(66.67)$ & 0.92 & $0.33-2.54$ & 0.871 \\
\hline \multicolumn{6}{|c|}{ Religion } \\
\hline Christian & $114(34.34)$ & $218(65.66)$ & & - & - \\
\hline Muslim & $16(37.21)$ & $27(62.79)$ & 1 & - & - \\
\hline
\end{tabular}




\begin{tabular}{|c|c|c|c|c|c|}
\hline Hindu & $1(100.00)$ & $0(0.00)$ & 1.13 & $0.59-2.19$ & 0.71 \\
\hline None & $1(12.5)$ & $7(87.5)$ & 0.27 & $0.03-2.25$ & 0.228 \\
\hline \multicolumn{6}{|c|}{ Household Head Gender } \\
\hline Male & $32(34.78)$ & $60(65.22)$ & 0.62 & $0.39-0.99$ & 0.048 \\
\hline Female & $100(34.25)$ & $192(65.75)$ & & - & - \\
\hline \multicolumn{6}{|c|}{ Level Of Education } \\
\hline None & $2(9.09)$ & $20(90.91)$ & & - & - \\
\hline Primary incomplete & $0(0.00)$ & $32(100)$ & 1 & - & - \\
\hline Primary complete & $10(22.22)$ & $35(77.78)$ & 2.86 & $0.57-14.36$ & 0.203 \\
\hline Secondary incomplete & $6(16.67)$ & $30(83.33)$ & 2 & $0.37-10.92$ & 0.423 \\
\hline Secondary complete & $60(41.96)$ & $83(58.04)$ & 7.23 & $1.63-32.11$ & 0.009 \\
\hline Tertiary incomplete & $6(30.00)$ & $14(70.00)$ & 4.29 & $0.75-24.42$ & 0.101 \\
\hline Tertiary complete & $48(55.81)$ & $38(44.19)$ & 12.63 & $2.78-57.44$ & 0.001 \\
\hline \multicolumn{6}{|c|}{ Employment Status } \\
\hline Unemployed & $111(28.91)$ & $18(16.22)$ & & - & - \\
\hline Casual worker & $81(21.09)$ & $30(37.04)$ & 3.04 & $1.54-5.98$ & 0.001 \\
\hline Formal employed & $39(10.16)$ & $34(87.18)$ & 35.13 & $12.10-102.00$ & $<0.001$ \\
\hline Self employed & $153(39.84)$ & $50(32.68)$ & 2.51 & $1.37-4.60$ & 0.003 \\
\hline \multicolumn{6}{|c|}{ Monthly Income } \\
\hline$<$ KSh 5000 & $169(44.01)$ & $31(18.34)$ & & - & - \\
\hline KSh 5000 - 10000 & $110(28.65)$ & $39(35.45)$ & 2.45 & $1.41-4.25$ & 0.001 \\
\hline KSh 10001 - 15000 & $62(16.15)$ & $30(48.39)$ & 4.17 & $2.22-7.85$ & $<0.001$ \\
\hline$>\operatorname{ksh} 15000$ & $43(11.20)$ & $32(74.42)$ & 12.95 & $5.89-28.48$ & $<0.001$ \\
\hline
\end{tabular}

Table 3: Bivariate Logistic Regression on Socio-Demographic Factors Affecting National Health Insurance Uptake.

This section represents multivariate analysis result after bivariate analysis. Binary logistic regression was used due to the nature of the dependent variable (0/1). Marital status and religion that were found to be statistically insignificant were dropped before running model for multivariate logistic regression. However, similar variables that were statistically significant in bivariate analysis were found to be significant in multivariate analysis.

In the variable age group, those who were $50+$ years were 6 times more likely to enroll for national health insurance as compared to the young people. Gender was also found to be a significant factor, female were 2.14 times more likely to enroll for national health insurance as compared to male. The results further reveal that people were 0.34 times less likely to register for national health insurance if the household head was male as compared to if the household head was female. Level of education was found to be a significant factor that determines uptake of national health insurance. As expected, level of education influence uptake of national health insurance positively. Taking those who had no formal education as the reference level, those who completed secondary were 12.20 times more likely to enroll for national health insurance and those who completed tertiary were 15.66 times more likely to enroll for national health insurance

The findings confirm that employment status has significant impact on uptake of national health insurance in Vihiga Sub-county. Those who were doing formal jobs were 9.30 times more likely to enroll in national health insurance as compared to those who did not have jobs. The results reveal further that monthly income was a significant factor in determining the uptake of national health insurance. Those who earn KSh 5000 to KSh. 10000 were 2.42 times more likely to enroll for national health insurance as compare to those who were earning below KSh. 5000. Those who were earning KSh 10001 to KSh. 15000 were 3.26 times more likely to enroll for national health insurance as compare to those who were earning below KSh. 5000 and also those who were earning $>$ KSh. 15000 were 6.88 times more likely to enroll for national health insurance as compare to those who 
were earning below KSh. 5000 .

\begin{tabular}{|c|c|c|c|c|c|}
\hline \multicolumn{6}{|c|}{ Uptake of National Health Insurance } \\
\hline Factors & Yes n(\%) & No $n(\%)$ & OR & 95\%CI & p-value \\
\hline Age group & $18(22.22)$ & $63(77.78)$ & & & \\
\hline$<30$ & $58(31.52)$ & $126(68.48)$ & & - & - \\
\hline $30-49$ & $56(47.06)$ & $63(52.94)$ & 2.33 & $1.00-5.41$ & 0.05 \\
\hline 50 and above & $18(22.22)$ & $63(77.78)$ & 6 & $2.45-14.70$ & $<0.001$ \\
\hline \multicolumn{6}{|c|}{ Gender } \\
\hline Male & $51(27.72)$ & $133(72.28)$ & & - & - \\
\hline Female & $81(40.5)$ & $119(59.5)$ & 2.14 & $1.19-3.86$ & 0.012 \\
\hline \multicolumn{6}{|c|}{ Household head gender } \\
\hline Male & $32(34.78)$ & $60(65.22)$ & 0.34 & $0.16-0.69$ & 0.003 \\
\hline Female & $100(34.25)$ & $192(65.75)$ & & & \\
\hline \multicolumn{6}{|c|}{ Education } \\
\hline None & $2(9.09)$ & $20(90.91)$ & & - & - \\
\hline Primary incomplete & $0(0.00)$ & $32(100)$ & 1 & - & - \\
\hline Primary complete & $10(22.22)$ & $35(77.78)$ & 4.61 & $0.82-25.96$ & 0.083 \\
\hline Secondary incomplete & $6(16.67)$ & $30(83.33)$ & 2.38 & $0.39-14.48$ & 0.345 \\
\hline Secondary complete & $60(41.96)$ & $83(58.04)$ & 12.2 & $2.41-61.71$ & 0.002 \\
\hline Tertiary incomplete & $6(30.00)$ & $14(70.00)$ & 6.26 & $0.89-44.02$ & 0.065 \\
\hline Tertiary complete & $48(55.81)$ & $38(44.19)$ & 15.66 & $2.96-82.84$ & 0.001 \\
\hline \multicolumn{6}{|c|}{ Employment status } \\
\hline Unemployed & $111(28.91)$ & $18(16.22)$ & & - & - \\
\hline Casual worker & $81(21.09)$ & $30(37.04)$ & 2.29 & $0.97-5.37$ & 0.058 \\
\hline Formal employed & $39(10.16)$ & $34(87.18)$ & 9.3 & $2.54-34.02$ & 0.001 \\
\hline Self employed & $153(39.84)$ & $50(32.68)$ & 1.47 & $0.69-3.15$ & 0.317 \\
\hline \multicolumn{6}{|c|}{ Monthly income } \\
\hline$<$ KSh 5000 & $169(44.01)$ & $31(18.34)$ & & - & - \\
\hline KSh $5000-10000$ & $110(28.65)$ & $39(35.45)$ & 2.42 & $1.22-4.77$ & 0.011 \\
\hline KSh 10001-15000 & $62(16.15)$ & $30(48.39)$ & 3.26 & $1.43-7.43$ & 0.005 \\
\hline$>\operatorname{ksh} 15000$ & $43(11.20)$ & $32(74.42)$ & 6.88 & $2.34-20.23$ & $<0.001$ \\
\hline
\end{tabular}

Table 4: Multivariate Logistic Regression on Socio-Demographic Factors Influencing National Health Insurance Uptake.

\section{Discussion}

Consistent with previous studies, findings from this study demonstrated the likelihood of health insurance enrolment increasing with age. It was found that those who were $50+$ were 6 times more likely to enroll for national health insurance as compared to the young people $(<30$ years). One possible explanation for this outcome is that financial security increases with age, which in turn increases the ability to purchase health insurance policies [5]. Also as people age and become older they are predisposed to various conditions and diseases as a result the health status reduces increasing the need for healthcare utilization and more importantly the purchase of health insurance [2]. Young adults tend to assume that they are healthy; they may also not have additional family responsibilities such as meeting the needs of children which may push them to taking up the insurance. Uninsured persons be it young adults or the old have less access to recommended care, receive poor quality of care, and experience worse health outcomes than insured 


\section{Public Health Open Access}

people do hence the need for increasing sensitization on the importance of health insurance.

Level of education was significantly associated with health insurance uptake. Completing secondary level of education was 12.20 times associated with enrolling for national health insurance. The results further reveal that respondents who completed tertiary level of education were 15.66 times more likely to enroll for national health insurance in comparison to those who had no formal education. These results concur with previous studies. An increase in education significantly increased insurance affiliation for both younger and older adults [8]. Higher education makes people better understand and appreciate the insurance concept and its benefits [2]. Education can impart a variety of benefits that improve the health trajectory of an individual. It exposes people to a wealth of information that prompts them to make healthier choices; access to healthcare services is one element of the equation that can't be ignored. Those with higher levels of education are less likely to face unemployment, but they're more likely to obtain employment that offers higher incomes with better health insurance leading to better access to quality care. Education also enhances information-seeking behavior and understanding of government and insurance company policies and programs. There was a significant relationship between the employment status and health insurance uptake. From the results, those who were doing formal jobs were 9.30 times more likely to enroll in national health insurance as compared to those who did not have jobs. This reinforces the fact that work can lead to better health and this is because of the financial benefits that come with being employed. Well-paying work provides individuals with the financial means to access health care in that people with higher incomes are more likely to have a regular provider of medical care and health insurance. Given that poverty leads to poor health status, employment increases household income and decreases economic hardship.

The result further confirms that household monthly income influence the uptake of national health insurance. Those earning KSh 5000 to KSh. 10000 were 2.42 times more likely to enroll for national health insurance. Those who were earning KSh 10001 to KSh. 15000 were 3.26 times more likely to enroll for national health insurance and also those who were earning $>$ KSh. 15000 were 6.88 times more likely to enroll for national health insurance. This is inconsistent to Maina JM, et al. [11] who reported household income as having no significant influence on uptake of health insurance this was because the effect of catastrophic financial effects was not anticipated in the group that was studied as they felt that the paying of insurance would have a minimal effect on the ability to cater for the basic needs. The results from this study is important as increased income lifts individuals above the poverty threshold and improves the health status as households are able to buy more health inputs that is housing, medical care and nutrition.

The results show that females were 2.14 times more likely to enroll for national health insurance as compared to the males. This is consistent with Duku S [2] who showed females are significantly more likely to enroll in the National Hospital Insurance Scheme than males. Women are the greatest users of health care, they act as care-givers for children and other sick members of the household, therefore they are likely to have positive attitude towards insurance than their male counterparts [7]. It is further revealed that if the household head is male, the respondent was 0.34 times less likely to enroll for national health insurance as compared to if the household head is female. This was consistent with Kimani JK, et al. [5] who found out that woman headed households are more likely to be insured. Women, represent the more vulnerable in society in terms of health care utilization and they are at times excluded from the scheme due to high premium rate, power relations within the households, class structure, political and geographical reasons therefore there is need to educate women on the importance of health insurance enrollment.

Marital status did not have any significant association with uptake of health insurance however $35.22 \%$ of the respondents that were married had been enrolled in a health insurance scheme. This was consistent with results from previous studies Duku S, [2], Kimani JK, et al. [5] where married individuals were more likely to be insured when compared to their other counterparts. Having a spouse/ partner is beneficial possibly because of the financial support derived from being in a dual-income household, which translates into more opportunities for accessing health insurance coverage also a spouse/partner can be insured through the other's insurance coverage from the employer [5]. In addition married individuals have additional responsibilities they therefore purchase health insurance to mitigate the financial burden that is likely to accrue from raising children [2].

\section{Conclusion}

This paper explored the role of demographic factors on health insurance uptake. The results of the logistic regression show that age, gender, gender of the household head, level of education, employment status and household monthly income were statistically significant.

\section{Recommendations}

Education should be encouraged by all stake holders involved and at all levels as it enhances information-seeking behavior. The government and other health insurance 
providers should come up with attractive options that will encourage the informal sector to enroll in health insurance schemes. It's further recommended that the government and other health insurance providers come up with measures that seek to encourage enrollment among the youth and the male category, this will ensure that they have access to recommended care, receive quality care, and experience better health outcomes.

\section{Conflict of Interests}

Authors declare no conflicts of interest.

\section{Funding}

The authors did not receive any grant for the study. The expenses for the study were fully met by the corresponding author Mrs. Marion Agiza Muranda.

\section{Informed Consent}

Written consent was obtained from the community members prior to starting the study.

\section{Authors' Contributions}

Marion Agiza Muranda wrote the first draft of the manuscript, Dr. Jane Adhiambo Owenga, Dr. David Odongo Otieno, Dr. Daniel Ogungu Onguru and Merceline Awino Orende reviewed and made inputs into the intellectual content and agreed on its submission for publication.

\section{References}

1. Ramos AL, Hoffmann F, Spreckelsen 0 (2018) Waiting times in primary care depending on insurance scheme in Germany. BMC health services research 18(1): 191.

2. Duku S (2018) Differences in the determinants of health insurance enrolment among working-age adults in two regions in Ghana. BMC health services research 18(1): 384.

3. Grossman M (1999) The human capital model of the demand for health. National Bureau of Economic Research, pp: 1-102.

4. Fadlallah R, El-Jardali F, Hemadi N, Morsi R, Samra C, et al. (2018) Barriers and facilitators to implementation, uptake and sustainability of community-based health insurance schemes in low-and middle-income countries: a systematic review. Int J Equity Health 17(1): 13.

5. Kimani JK, Ettarh R, Warren C, Bellows B (2014) Determinants of health insurance ownership among women in Kenya: evidence from the 2008-09 Kenya demographic and health survey. Int J Equity Health 13: 27.

6. Perlman F, Balabanova D, McKee M (2009) An analysis of trends and determinants of health insurance and healthcare utilisation in the Russian population between 2000 and 2004: the'inverse care law'in action. BMC health Serv Res 9(1): 68.

7. Boateng D, Awunyor VD (2013) Health insurance in Ghana: evaluation of policy holders' perceptions and factors influencing policy renewal in the Volta region. Int J Equity Health 12(1): 50.

8. Wielen VDN, Falkingham J, Channon AA (2018) Determinants of National Health Insurance enrolment in Ghana across the life course: Are the results consistent between surveys? Int J Equity Health 17: 49.

9. Cantiello J, Fottler MD, Oetjen D, Zhang NJ (2015) The impact of demographic and perceptual variables on a young adult's decision to be covered by private health insurance. BMC Health Services Research 15: 195.

10. Oraro T, Wyss K (2018) How does membership in local savings groups influence the determinants of national health insurance demand? A cross-sectional study in Kisumu, Kenya. Int J Equity Health 17(1): 170.

11. Maina JM, Kithuka P, Tororei S (2016) Perceptions and uptake of health insurance for maternal care in rural Kenya: a cross sectional study. Pan Afr Med J 23: 125.

12. Mukhwana E, Ngaira JK, Mutai C (2015) Determinants of Uptake and Utilization of National Hospital Insurance Fund Medical Cover by People in the Informal Sector in Kakamega County, Kenya., 4. Universal Journal of Public Health 3(4): 169-176.

13. Odeyemi I, Nixon J (2013) The role and uptake of private health insurance in different health care systems: are there lessons for developing countries? Clinicoecon Outcomes Res 5: 109-118.

14. Adebayo EF, Uthman OA, Wiysonge CS, Stern EA, Lamont KT, et al. (2015) A systematic review of factors that affect uptake of community-based health insurance in lowincome and middle-income countries. BMC health Serv Res 15: 543.

15. Kimani JK, Ettarh R, Kyobutungi C, Mberu B, Muindi K (2012) Determinants for participation in a public health insurance program among residents of urban slums in Nairobi, Kenya: results from a cross-sectional survey. BMC health Ser Res 12: 66. 
16. Manortey S, Alder S, Crookston B, Dickerson $\mathrm{T}$, VanDerslice J, et al. (2014) Social deterministic factors to participation in the National Health Insurance Scheme in the context of rural Ghanaian setting. J public health Afr 5(1): 352.
17. Katindi SN (2013) Exploring Kenya's Inequality; Pulling Apart or Pulling Together. Kenya National Bureau of Statistics, Society for International Development, pp: $1-56$.

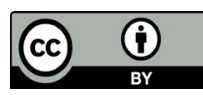

